OPEN ACCESS

Edited by:

Alejandro Lazo-Langner

Western University (Canada), Canada

Reviewed by:

Sam Schulman,

McMaster University, Canada

Wei Li,

Marshall University, United States

*Correspondence:

Nicolas Gendron

nicolas.gendron@aphp.fr

Specialty section:

This article was submitted to

Pathology,

a section of the journal

Frontiers in Medicine

Received: 27 August 2020 Accepted: 10 November 2020 Published: 16 December 2020

Citation: Gendron N, Chocron R, Billoir $P$

Brunier J, Camoin-Jau L, Tuffigo M,

Faille D, Teissandier D, Gay J, de

Raucourt E, Suner L, Bonnet $C$

Martin A-C, Lasne D, Ladhari C, Lebreton A, Bertoletti L, Ajzenberg N,

Gaussem P, Morange P-E, Le Cam Duchez V, Viallon A, Roy P-M, Lillo-le

Louët $A$ and Smadja DM (2020)

Dabigatran Level Before Reversal Can

Predict Hemostatic Effectiveness of Idarucizumab in a Real-World Setting.

Front. Med. 7:599626.

doi: 10.3389/fmed.2020.599626

\section{Dabigatran Level Before Reversal Can Predict Hemostatic Effectiveness of Idarucizumab in a Real-World Setting}

\author{
Nicolas Gendron ${ }^{1,2 *}$, Richard Chocron ${ }^{3,4}$, Paul Billoir ${ }^{5}$, Julien Brunier ${ }^{6}$, \\ Laurence Camoin-Jau ${ }^{7}$, Marie Tuffigo ${ }^{8}$, Dorothée Faille ${ }^{9,10}$, Dorian Teissandier ${ }^{11}$, \\ Juliette Gay ${ }^{1,12}$, Emmanuelle de Raucourt ${ }^{13,14}$, Ludovic Suner ${ }^{15}$, Corentin Bonnet ${ }^{16}$, \\ Anne-Céline Martin ${ }^{1,17}$, Dominique Lasne ${ }^{18}$, Chayma Ladhari ${ }^{19}$, Aurélien Lebreton ${ }^{20}$, \\ Laurent Bertoletti ${ }^{21,22}$, Nadine Ajzenberg ${ }^{9,10}$, Pascale Gaussem ${ }^{1,12}$, \\ Pierre-Emmanuel Morange ${ }^{7,22,23}$, Véronique Le Cam Duchez ${ }^{5}$, Alain Viallon ${ }^{24}$, \\ Pierre-Marie Roy ${ }^{22,25}$, Agnès Lillo-le Louët ${ }^{1,26}$ and David M. Smadja ${ }^{1,2,22}$
}

${ }^{1}$ Université de Paris, Innovative Therapies in Haemostasis, INSERM, Paris, France, ${ }^{2}$ Hematology Department and Biosurgical Research Lab (Carpentier Foundation), AH-HP, Georges Pompidou European Hospital, Paris, France, ${ }^{3}$ Université de Paris, PARCC, INSERM, Paris, France, ${ }^{4}$ Emergency Department, AH-HP, Georges Pompidou European Hospital, Paris, France, ${ }^{5}$ Normandie Univ, UNIROUEN, INSERM Rouen University Hospital, Vascular Hemostasis Unit, Rouen, France,

${ }^{6} \mathrm{CHU}$-Pellegrin, Laboratory of Hematology, Bordeaux, France, ${ }^{7}$ AP-HM, CHU Timone, Laboratory of Hematology, Marseille, France, ${ }^{8} \mathrm{CHU}$ Angers, Laboratory of Hematology, Angers, France, ${ }^{9}$ Université de Paris, Laboratory of Vascular Translational Science, INSERM, Paris, France, ${ }^{10}$ Laboratory of Hematology, AH-HP, Bichat Hospital, Paris, France, ${ }^{11} \mathrm{CHU}$

Clermont-Ferrand, Emergency Medicine Department, Clermont-Ferrand, France, ${ }^{12}$ Hematology Department, AH-HP, Georges Pompidou European Hospital, Paris, France, ${ }^{13}$ Université de Paris, LVTS, INSERM, Paris, France, ${ }^{14}$ Hematology Department, AP-HP, Hôpital Beaujon, Clichy, France, ${ }^{15}$ Sorbonne Université, Inserm, Centre de Recherche Saint-Antoine, AP-HP, Hôpital Saint-Antoine, Hématologie Biologique, Paris, France, ${ }^{16} \mathrm{CHU}$ Sud Réunion, Anaestesiology Department, Saint-Pierre, La Réunion, France, ${ }^{17}$ Cardiology Department, AH-HP, Georges Pompidou European Hospital, Paris, France, ${ }^{18} \mathrm{AP}-\mathrm{HP}, \mathrm{CHU}$ Necker-Enfants Malades, Department of Biogical Hematology, Paris, France, ${ }^{19} \mathrm{CHU}$ Montpellier, Centre Régional de Pharmacovigilance, Montpellier, France, ${ }^{20} \mathrm{CHU}$ Clermont-Ferrand, Laboratory of Hematology, Clermont-Ferrand, France, ${ }^{21}$ Service de Médecine Vasculaire et Thérapeutique, CHU de Saint-Étienne, INSERM, Université Jean-Monnet, INSERM, CHU de Saint-Étienne, Saint-Étienne, France, ${ }^{22}$ F-CRIN INNOVTE, Saint-Étienne, France, ${ }^{23}$ C2VN, Aix Marseille Univ, INSERM, INRAE, C2VN, Marseille, France, ${ }^{24} \mathrm{CHU}$ Saint-Étienne, Emergency Department, Saint-Étienne, France, ${ }^{25} \mathrm{CHU}$ Angers, Emergency Department and Vascular Medicine Ward, Université d'Angers, MITOVASC Institut, UMR (CNRS 6015-INSERM 1083), Angers, France, ${ }^{26}$ Département de Pharmacovigilance, AH-HP, Georges Pompidou European Hospital, Paris, France

Background: Idarucizumab has been included in guidelines for the management of bleeding or surgical procedure in dabigatran-treated patients without need for biological monitoring. The aim of the study was to assess the prognostic value of dabigatran plasma level before reversal to test the hemostatic efficacy of idarucizumab. The secondary objectives were (i) to analyze plasma dabigatran level according to the risk of rebound and (ii) to evaluate the incidence of post-reversal non-favorable clinical outcomes (including thromboembolism, bleeding, antithrombotic, and death) and antithrombotic resumption.

Methods and Results: This was an observational multicentric cohort study, which included all French patients who required idarucizumab for dabigatran reversal. Between May 2016 and April 2019, 87 patients from 21 French centers were enrolled. Patients received idarucizumab for overt bleeding $(n=61)$, urgent procedures $(n=24)$, 
or overdose without bleeding $(n=2)$. Among patients with major bleeding ( $n=57)$, treatment with idarucizumab was considered effective in $44(77.2 \%)$ of them. Patients who did not achieve effective hemostasis after reversal had a significantly higher mean level of plasma dabigatran at baseline (524.5 $\pm 386 \mathrm{vs}$. $252.8 \mathrm{ng} / \mathrm{mL} \pm 235, p=0.033$ ). Furthermore, patients who did not achieve effective hemostasis after reversal had less favorable outcomes during follow-up (46.2 vs. 81.8\%, $p=0.027$ ). ROC curve identified a cutoff of $264 \mathrm{ng} / \mathrm{mL}$ for dabigatran level at admission to be predictive of ineffective hemostasis. No plasma dabigatran rebound was observed after reversal in patients with dabigatran plasma level $<264 \mathrm{ng} / \mathrm{mL}$ at baseline.

Conclusion: This retrospective study shows that dabigatran level before reversal could predict hemostatic effectiveness and dabigatran plasma rebound after idarucizumab injection.

Keywords: idarucizumab, dabigatran, reversal, bleeding, hemostatic effectiveness, rebound, perioperative

\section{INTRODUCTION}

The specific reversal agent idarucizumab is a humanized monoclonal antibody fragment that binds dabigatran with a very high affinity. The RE-VERSE AD trial (1) showed the efficacy and safety of idarucizumab to reverse the anticoagulant effect of dabigatran within $4 \mathrm{~h}$ after its administration in dabigatran-treated patients who experienced serious bleeding or required urgent invasive procedures. Although small case series $(2,3)$ on the use of idarucizumab have been reported, there are only three large studies in a real-world setting. First, a cohort of 20 hospitals in the Netherlands (4) enrolled 88 patients; among them, 53 had severe bleeding, and 35 required urgent surgical intervention. Effective hemostasis was achieved in two-thirds of bleeding patients and was associated with a lower mortality risk. Clinical outcomes were considered similar to those observed in the RE-VERSE AD trial, regarding recurrent bleeding, thromboembolism, and mortality rate. Second, a large national multicentric retrospective study from the United States (5) included 266 patients exposed to idarucizumab who were compared to 1,345 non-exposed patients. In patients with gastrointestinal bleeding (GIB), there was no difference in terms of in-hospital mortality between patients exposed to idarucizumab and those non-exposed, but in case of intracranial hemorrhage (ICH), an increased risk of mortality was reported among patients exposed to idarucizumab. Third, a German national retrospective study (6) enrolled 120 dabigatran-treated patients who received idarucizumab, 80 of whom with ischemic stroke and 40 with intracranial bleeding (ICH in 27 patients). In patients receiving intravenous thrombolysis following idarucizumab, $78 \%$ showed a median improvement on the National Institutes of Health Stroke Scale. Moreover, hematoma growth was observed in $11.1 \%$ of patients with ICH.

According to international guidelines, idarucizumab is indicated in dabigatran-treated patients in case of life-threatening and/or uncontrolled bleeding or situations requiring a rapid reversal of dabigatran anticoagulant effects such as urgent surgery. However, no specific dabigatran monitoring is currently recommended either before reversal or during follow-up (7) due to the lack of consistent biological data during clinical trials. However, reappearance or a rebound of dabigatran levels was observed in $23.0 \%$ patients in RE-VERSE AD trial (1). Since then, several cases of reversal failure, plasma dabigatran rebound and/or re-bleeding have been published $(2,3,8,9)$. Interestingly, we previously demonstrated that a risk of rebound in circulating dabigatran after reversal could be predicted by an initial dabigatran plasma level above $200 \mathrm{ng} / \mathrm{mL}$. In this context of bleeding or emergency procedures, it is important to note that routine hemostasis testing, such as prothrombin time and activated partial thrombin time, is inappropriate to monitor the dabigatran level $(10,11)$.

Our study describes retrospective data collected from 21 French centers from May 2016 to April 2019. The aim was to assess the relationship between dabigatran level before reversal with idarucizumab and the evolution of patients-in particular, hemostatic effectiveness in patients who received idarucizumab for major bleeding or who needed urgent procedures. This study also assessed the prognostic value of dabigatran plasma level at admission to evaluate the risk of rebound and clinical outcomes.

\section{MATERIALS AND METHODS Study Design and Setting}

This observational retrospective cohort study included all French patients who had received idarucizumab for dabigatran reversal and who were reported to the French pharmacovigilance network. Data from patients were retrospectively collected from institutions by a nationwide survey conducted by the French pharmacovigilance centers from May 2016 to April 2019. No exclusion criteria were applied. The study was performed in accordance with the Declaration of Helsinki. The institutional review board of each center approved the study, and anonymous data collection was declared to the appropriate authorities (authorization protocol number: CNIL-1922081). 


\section{Data Collection}

Baseline characteristics of patients (demographic, clinical, cardiovascular risk factors, $\mathrm{CHA}_{2} \mathrm{DS}_{2}$-VASc score, and body mass index), and surgical and biological data were retrieved from the pharmacovigilance reports and the medical records. Indication for the use of idarucizumab was recorded: lifethreatening or uncontrolled bleeding requiring medical intervention, emergency surgery, or invasive procedure, and any other setting including dabigatran overdose. Additional blood products and/or pro-hemostatic agents used during reversal, patient's outcomes, and antithrombotic resumption data were also retrieved from the medical records. Creatinine clearance $(\mathrm{CrCl})$ was calculated using the Cockcroft and Gault formula.

\section{Study Outcomes}

The primary objective was to assess the prognostic value of dabigatran plasma level tested before reversal with idarucizumab to evaluate the hemostatic effectiveness in major bleeding patients.

The secondary objectives were (i) to analyze plasma dabigatran level according to the risk of rebound to replicate our previous study (3). Rebound was defined as an increase in the plasma concentration above the $30 \mathrm{ng} / \mathrm{mL}$ threshold of detection after reversal and (ii) to evaluate the incidence of non-favorable clinical outcomes including symptomatic thromboembolism, rebleeding or non-cessation of the bleeding, allergic reaction, and deaths at 5, 30, and 90 days after dabigatran reversal. Furthermore, antithrombotic resumption after reversal and timing for resuming antithrombotic was also reported.

\section{Definition of Dabigatran-Related Bleeding}

Information regarding the location of bleeding events (GIB, $\mathrm{ICH}$, or other defined locations) was collected. All bleeding dabigatran-related events that needed idarucizumab injection were reviewed retrospectively by two hematologists (NG and DMS) and classified according to the criteria of the International Society on Thrombosis and Haemostasis (ISTH) (12). In short, major bleeding was defined as fatal bleeding or symptomatic bleeding in a critical area or organ or bleeding causing a hemoglobin level of $20 \mathrm{~g} / \mathrm{L}$ or more or leading to transfusion of $>2 \mathrm{U}$ of packed red blood cells (PRBCs). Since all patients included in this study were hospitalized to receive idarucizumab, non-major bleeding fulfilled non-major clinically relevant criteria (13) defined as any sign or symptom of hemorrhage that did not meet the criteria for the ISTH definition of major bleeding, but did meet at least one of the following criteria: (i) requiring medical intervention by a healthcare professional; (ii) leading to hospitalization or increased level of care; or (iii) prompting a face-to-face evaluation.

Effective clinical hemostasis after treatment of a major bleeding using idarucizumab was reviewed and classified as binary outcome, i.e., effective or ineffective according to the ISTH criteria (14). For this assessment, medical records were screened for hemoglobin level, transfusion, invasive procedures reports, and diagnostic imaging reports.

\section{Statistical Analysis \\ Descriptive Analysis}

Continuous data were expressed as mean \pm standard deviation (SD). Categorical data were expressed in numbers $(n)$ and percentages. We compared patient and biological characteristics at admission after dabigatran reversal according to idarucizumab indication (bleeding, urgent procedure, and other), to hemostatic effectiveness, to initial plasma dabigatran level $(\geq 264 \mathrm{ng} / \mathrm{mL})$ and to dabigatran rebound, using Fisher's exact test for categorical variables and Mann-Whitney-Wilcoxon test for continuous variables $(15,16)$. We also compared patient characteristics and outcomes after dabigatran reversal according to renal function using the Cochran-Armitage test for trend for categorical variables and the Kruskal-Wallis test for continuous variables (17).

\section{Assessment of the Initial Dabigatran Plasma Level as a Biomarker of Hemostatic Efficacy}

We generated a receiver operating characteristic (ROC) curve $(18,19)$ to assess the prognostic value of plasma dabigatran level before reversal in regard to the hemostatic efficacy of idarucizumab and to find an appropriate cutoff point of dabigatran plasma measurement as biomarker. We calculated the area under the curve (AUC).

We used the Kaplan Meier survival curve and the log rank test to compare time with plasma dabigatran rebound and overall survival after reversal according to identified dabigatran cutoff before reversal $(20,21)$.

We used logistic regression to determine whether the level of dabigatran (as a categorical dependent variable dichotomized according to the cutoff of $264 \mathrm{ng} / \mathrm{mL}$ ) adjusted on the $\mathrm{CrCl}$ (as a categorical dependent variable dichotomized according to the cutoff of $30 \mathrm{~mL} / \mathrm{min}$ ) was associated with the hemostatic efficacy (22).

All analyses were two-sided, and a $p$-value lower than 0.05 was considered to be significant. Statistical analysis was performed using $\mathrm{R}$ studio software [RStudio Team (2015). RStudio: Integrated Development for R. RStudio, Inc., Boston, MA, USA].

\section{RESULTS}

\section{Characteristics of Study Subjects}

From May 2016 to April 2019, 21 French centers enrolled 87 patients who received 92 injections of idarucizumab for dabigatran reversal. The demographic, clinical, and biological characteristics of patients are reported in Table 1. Briefly, the mean age of patients was 79.7 years, and $62.1 \%$ were males. Mean $\mathrm{CrCl}$ at admission was $50.5 \mathrm{~mL} / \mathrm{min}$. Almost all patients were treated with dabigatran for non-valvular atrial fibrillation (95.4\%), of whom $60.9 \%$ received the $110 \mathrm{mg}$ twice-daily dose. Idarucizumab injections were administered to $61(70.1 \%)$ patients for overt bleeding, in $24(27.6 \%)$ patients for various urgent procedures, and in two $(2.3 \%)$ for dabigatran overdose without bleeding. Outcomes of patients from these three patient groups are detailed in Supplementary Tables 1-3. Most events 
TABLE 1 | Patient characteristics at admission and outcomes after dabigatran reversal.

\begin{tabular}{|c|c|c|c|c|}
\hline Patient characteristics & Bleeding $(N=61)$ & Urgent procedure $(N=24)$ & Others* $(N=2)$ & All patients $(N=87)$ \\
\hline Age-year-mean ( $\pm S D)$ & $80.8( \pm 11.0)$ & $77.2( \pm 16.0)$ & $75.5( \pm 4.9)$ & $79.7( \pm 12.5)$ \\
\hline Male sex $-n(\%)$ & $37(60.7)$ & $17(70.8)$ & $0(0.0)$ & $54(62.1)$ \\
\hline $\mathrm{CHA}_{2} \mathrm{DS}_{2}$-VASc score-mean $( \pm \mathrm{SD})$ & $3.12( \pm 1.6)$ & $3.83( \pm 1.4)$ & $4.50( \pm 0.7)$ & $3.32( \pm 1.5)$ \\
\hline $\mathrm{BMl}-\mathrm{kg} / \mathrm{m}^{2}-\mathrm{mean}( \pm \mathrm{SD})$ & $25.6( \pm 4.1)$ & $26.9( \pm 4.3)$ & $30.6( \pm 6.2)$ & $26.2( \pm 4.3)$ \\
\hline $\mathrm{CrCl}-\mathrm{mL} / \mathrm{min}-\mathrm{mean}( \pm \mathrm{SD})$ & $50.8( \pm 25.6)$ & $53.9( \pm 24.2)$ & $7.9( \pm 4.1)$ & $50.5( \pm 25.1)$ \\
\hline Hemoglobin g/L-mean ( $\pm S D)$ & $108( \pm 34)$ & $129( \pm 30)$ & $100( \pm 28)$ & $114( \pm 34)$ \\
\hline \multicolumn{5}{|l|}{ Dose of dabigatran $-n(\%)$} \\
\hline 150 mg twice daily & $16(26.2)$ & $10(41.7)$ & $2(100.0)$ & $28(32.2)$ \\
\hline 110 mg twice daily & $40(65.6)$ & $13(54.2)$ & $0(0.0)$ & $53(60.9)$ \\
\hline 75 mg twice daily & $3(4.9)$ & $0(0.0)$ & $0(0.0)$ & $3(3.4)$ \\
\hline Missing data & $2(3.3)$ & $1(4.1)$ & $0(0.0)$ & $3(3.4)$ \\
\hline \multicolumn{5}{|l|}{ Indication for dabigatran $-n(\%)$} \\
\hline NVAF & $59(96.7)$ & $22(91.7)$ & $2(100.0)$ & $83(95.4)$ \\
\hline VTE & $1(1.6)$ & $2(8.3)$ & $0(0.0)$ & $3(3.4)$ \\
\hline Others & $1(1.6)$ & $0(0.0)$ & $0(0.0)$ & $1(1.1)$ \\
\hline \multicolumn{5}{|c|}{ Laboratory tests at baseline (before idarucizumab administration) } \\
\hline Prolonged aPTT-n/evaluable patients (\%) & $47 / 54(87.0)$ & 18/21 (85.7) & 2/2 (100.0) & $67 / 77(87.0)$ \\
\hline Prolonged PT-n/evaluable patients (\%) & $41 / 55(74.5)$ & 16/21 (76.2) & 2/2 (100.0) & $59 / 78(75.6)$ \\
\hline Dabigatran, ng/mL-mean ( \pm SD) & $327( \pm 303)$ & $125( \pm 134)$ & $1,014-2,881$ & $323( \pm 477)$ \\
\hline$\geq 2$ injections of idarucizumab $-n(\%)$ & $2(3.3)$ & $1(4.1)$ & $2(50.0)$ & $5(5.7)$ \\
\hline
\end{tabular}

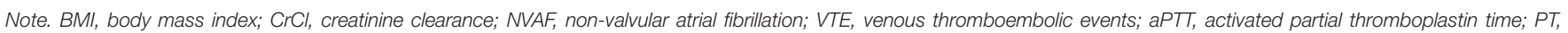
thromboplastin time.

"These two patients ( $n^{\circ} 86$ and $n^{\circ} 87$ ) received an idarucizumab injection for dabigatran overdose without bleeding.

TABLE 2 | Clinical and biological characteristics at admission of evaluable major bleeding patients with or without hemostatic effectiveness after dabigatran reversal.

\begin{tabular}{|c|c|c|c|}
\hline \multirow[t]{2}{*}{ Patient characteristics } & \multicolumn{2}{|c|}{ Hemostatic effectiveness } & \multirow[b]{2}{*}{$p$-Value } \\
\hline & Yes $(n=44)$ & No $(n=13)$ & \\
\hline Age-year-mean ( $\pm S D$ ) & $80.2( \pm 11.5)$ & $83.2( \pm 10.3)$ & 0.39 \\
\hline Male sex $-n(\%)$ & 28 (63.6) & 7 (53.8) & 0.75 \\
\hline $\mathrm{CHA}_{2} \mathrm{DS}_{2}$-VASc score-mean ( $\left.\pm \mathrm{SD}\right)$ & $3.1( \pm 1.5)$ & $3.3( \pm 1.9)$ & 0.71 \\
\hline $\mathrm{BMl}-\mathrm{kg} / \mathrm{m}^{2}-\mathrm{mean}( \pm \mathrm{SD})$ & $25.5( \pm 4.2)$ & $26.3( \pm 4.4)$ & 0.63 \\
\hline CrCl-mL/ min-mean ( \pm SD) & $48.5( \pm 24.5)$ & $58.7( \pm 29.2)$ & 0.24 \\
\hline Hemoglobin g/L-mean ( $\pm S D)$ & $107.0( \pm 34.1)$ & $112.31( \pm 34.4)$ & 0.63 \\
\hline Dabigatran-ng/mL-mean ( $\pm S D)$ & $252.8( \pm 235)$ & $524.5( \pm 386)$ & 0.033 \\
\hline Favorable outcome-n (\%) & $36(81.8)$ & $6(46.2)$ & 0.027 \\
\hline Death-n (\%) & $7(15.9)$ & $6(46.2)$ & 0.056 \\
\hline
\end{tabular}

$B M I$, body mass index; $\mathrm{CrCl}$, creatinine clearance. Bold values are corresponding to statistical differences with $p$-value $<0.005$.

in the bleeding group were GIB (50.8\%), ICH (34.2\%), and iliopsoas hematoma (4.9\%). Urgent procedures were varied and are reported in Supplementary Table 2. All patients were initially given the full dose of two vials $(2 \times 2.5 \mathrm{~g})$ of idarucizumab, whereas four $(4.6 \%)$ patients received a second dose, and only one received a third injection (Supplementary Table 4).

Blood products and prohemostatic agents were used in 46 (58.2\%) of 79 assessable patients (Supplementary Table 5). The most frequently used products were PRBCs. Regarding the bleeding group ( $n=61), 31(50.8 \%)$ patients received a mean of 1.49 ( \pm 1.8$)$ PRBC unit/patient. Otherwise, five (8.2\%) patients were given fresh frozen plasma and four (6.6\%) prothrombin complex concentrates (PCC). Multiple hemostatic agents were required for $9.8 \%(6 / 61)$ patients. Among patients requiring urgent surgery $(n=24)$, eight $(33.3 \%)$ received $1.10( \pm 1.7)$ unit of PRBC/patient, five (20.8\%) patients received fresh frozen plasma and two (8.3\%) PCC, and five (20.8\%) required multiple hemostatic agents. It should be noted that neither rFVIIa nor activated PCC was used.

After reversal, antithrombotic therapy was resumed in $47(54.0 \%)$ patients, $27(44.3 \%)$ from the bleeding group and $18(75.0 \%)$ from the urgent procedure group (Supplementary Table 6). Dabigatran was resumed in 15 (24.6\%) patients in the bleeding group and in $12(50.0 \%)$ patients in the urgent procedure group after a mean time of 11.5 days $( \pm 24.5)$ and 5.1 days $( \pm 6.8)$, respectively. According to the outcomes in the bleeding group, the mean time until antithrombotic resumption was 5.5 days $( \pm 4.6)$ for GIB and 33.4 days $( \pm 49.6)$ for ICH.

Among the study patients, $84(96.6 \%)$ had a laboratory test prior to idarucizumab administration. Specific dabigatran plasma measurement was available for 47 patients (59.4\%). Diluted thrombin time was used in most cases $(n=44)$. Three $(\# 37, \# 38$, and \#39) were quantified by LC/MS. Among evaluable patients, 79 (94.0\%) had abnormal hemostasis tests at baseline including prolonged PT, prolonged aPTT, and/or dabigatran plasma level $\geq 30 \mathrm{ng} / \mathrm{mL}$. 
TABLE 3 | Patient characteristics and outcomes after dabigatran reversal according to renal function.

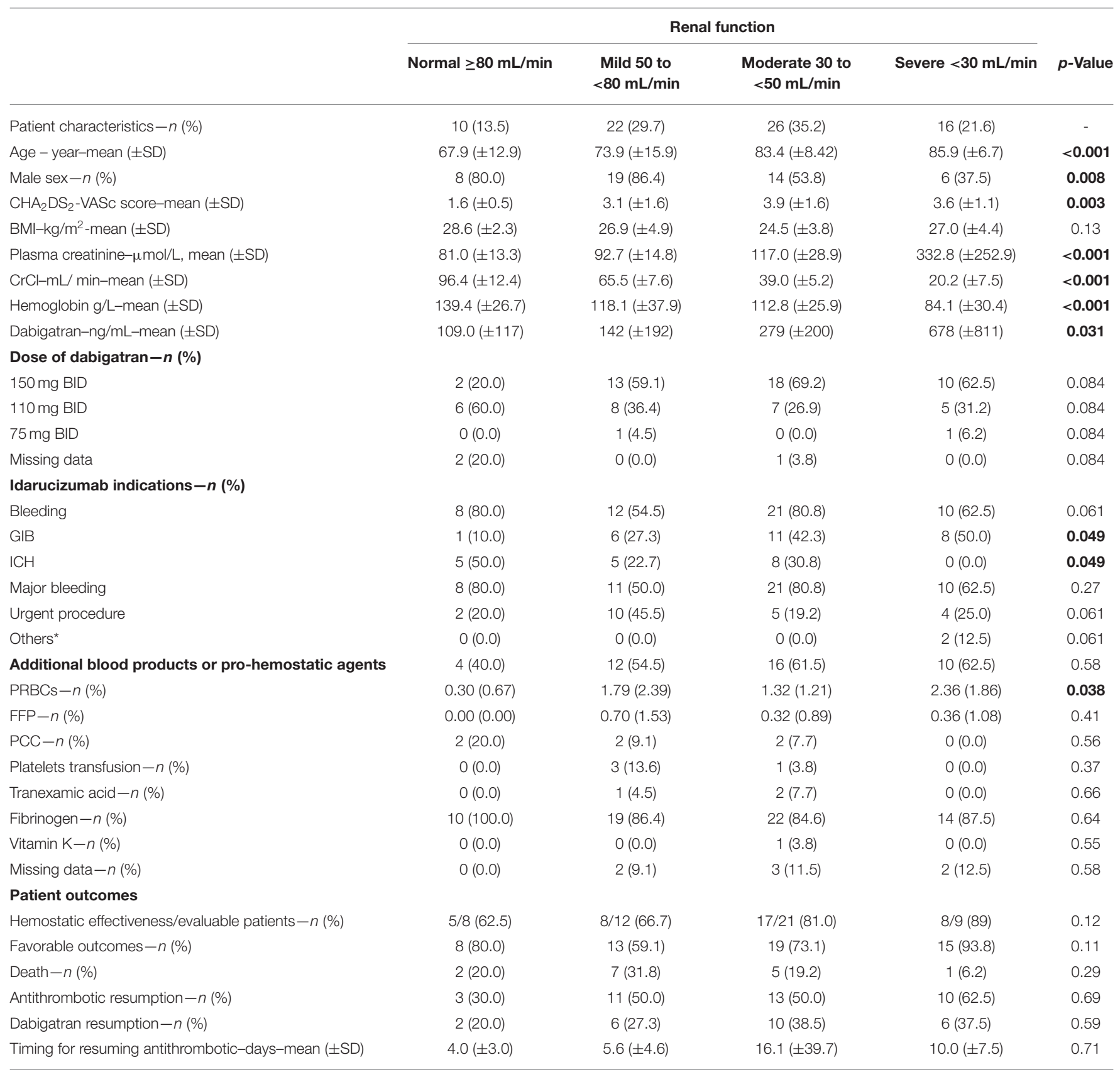

Characteristic of analyzable patients included in the study according to renal impairment $(n=74)$.

M, male; F, female; SD, standard deviation; BMI, body mass index; CrCl, creatinine clearance; BID, twice a day; GIB, gastrointestinal bleeding; ICH, intracranial hemorrhage; NA, non-available; PRBCs, packed red blood cells; FFP, fresh frozen plasma; PCC, prothrombin complex concentrate.

"Patients \#86 and \#87 received idarucizumab for dabigatran overdose without bleeding.

Bold values are corresponding to statistical differences with $p-$ value $<0.005$.

\section{Patient Post-Reversal Outcomes}

During a mean follow-up of 109 days ( \pm 190$), 65$ patients $(74.7 \%)$ had a favorable outcome (Supplementary Tables 1-3). Three thrombotic events (3.4\%) were reported: one pulmonary embolism, one stroke, and one catheter-related venous thrombosis in a cancer patient. One patient developed an anaphylactic reaction within minutes after idarucizumab injection. Eighteen patients died (20.7\%) during hospitalization or follow-up. More specifically, mortality rate at 5, 30, and 90 days was $16.4,19.7$, and $23.0 \%$, respectively, in the bleeding group, and $8.3,12.4$, and $16.7 \%$ in the urgent procedure group (Supplementary Table 7).

Causes of death are summarized in Supplementary Table 7. In the bleeding group, there were six $(9.8 \%)$ fatal bleedings, three 
(4.9\%) severe infections, three (4.9\%) multivisceral failures, one (1.6\%) cardiac arrest, and one (1.6\%) disseminated intravascular coagulation. In the urgent procedure group, there were two (8.3\%) fatal bleedings and two (8.3\%) multivisceral failures. After reversal, overall survival at 90 days did not significantly differ between the bleeding and the urgent procedure groups (Supplementary Figure 1, 79.3 vs. 83.3\%, $p=0.92$ ).

\section{Hemostatic Effectiveness of Idarucizumab}

Among the 61 patients admitted for bleeding, 58 (95.1\%) were considered as major bleeding events according to the ISTH criteria (12). Dabigatran reversal with idarucizumab was considered effective according to ISTH (14) in 44 out of 57 (77.2\%) evaluable patients (Table 2).

Patients who did not achieve effective hemostasis after reversal had a significantly higher mean level of dabigatran at admission (524 \pm 386 vs. $252 \mathrm{ng} / \mathrm{mL} \pm 235, p=0.033)$. Second, they experienced less favorable outcomes ( 46.2 vs. $81.8 \%, p=0.027$ ) during follow-up, with a trend to more deaths (46.2 vs. $15.9 \%, p$ $=0.056$ ). When classifying major bleeding patients according to renal function, we found that renal impairment was associated with increased baseline dabigatran level (Table 3), although effective hemostasis did not correlate with $\mathrm{CrCl}(p=0.23)$ nor with the distribution of renal function into four groups ( $p$ for trend test 0.12 and $\mathrm{p}$ for Pearson's chi-squared test 0.48 ).

Then the relationship between the dabigatran level before reversal and adjudicated hemostatic efficacy was evaluated by ROC curves. Overall, there was a significant relationship between hemostatic efficacy and baseline dabigatran level. For patients with major bleeding, the highest likelihood ratio corresponded to a plasma dabigatran $\geq 264 \mathrm{ng} / \mathrm{mL}$, which was a predictor of ineffective hemostasis, with an area under the ROC curve of 0.729 (95\% CI 0.50-0.97, Figure 1). This value had a sensitivity of $82.4 \%$ (95\% CI 55.0-92.0), a specificity of $75.0 \%$ (95\% CI $49.0-$ 90.0 ), and a negative predictive value of 66.6 (95\% CI 34.0-82.0) and a positive predictive value of 87.5 (95\% CI 62.0-97.0).

Next, to assess the relevance of this cutoff according to renal impairment, we used a multivariable logistic regression model evaluating dabigatran level $\geq 264 \mathrm{ng} / \mathrm{mL}$ and $\mathrm{CrCl}<30$ $\mathrm{mL} / \mathrm{min}$ for hemostatic effectiveness outcomes. Adjustment to $\mathrm{CrCl}$ was chosen as the Cockcroft and Gault formula based on age, sex, and weight of the patients. Indeed, when a logistic regression model used the cutoff of $30 \mathrm{~mL} / \mathrm{min}$ for $\mathrm{CrCl}$, the association between dabigatran level $<264 \mathrm{ng} / \mathrm{mL}$ and hemostatic effectiveness outcome remained significant [OR, 10.75 (95\% CI 1.40-229.83), $p=0.046]$.

\section{Patient Characteristics According to Baseline Dabigatran Level Cutoff of 264 $\mathrm{ng} / \mathrm{mL}$}

The $264 \mathrm{ng} / \mathrm{mL}$ cutoff as determined above was used to compare baseline characteristics of the 47 patients of the entire cohort who had a specific dabigatran plasma measurement before reversal (Table 4). At admission, patients with a dabigatran level $\geq 264 \mathrm{ng} / \mathrm{mL}$ had a significantly lower $\mathrm{CrCl}$ (31.8 \pm 20.8 vs. 50.7 $\mathrm{mL} / \mathrm{min} \pm 25.1, p=0.019)$ and a significantly lower hemoglobin

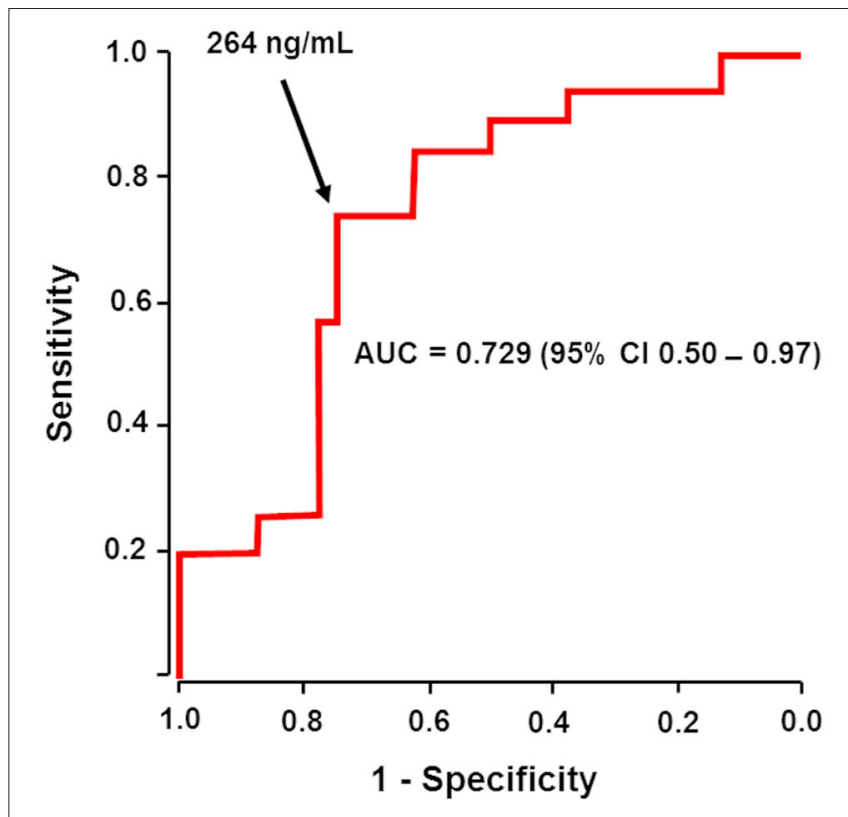

FIGURE 1 | Initial plasma dabigatran could predict hemostatic effectiveness after reversal. The receiver operating characteristic (ROC) area under the curve (AUC) of the association between baseline plasma dabigatran level and hemostatic efficacy (effective or ineffective) in evaluable patients with major bleeding receiving idarucizumab. Arrow shows that a dabigatran level higher than $264 \mathrm{ng} / \mathrm{mL}$ before reversal was a predictor of ineffective hemostasis, with an area under the ROC curve of 0.729 (95\% Cl $0.50-0.97)$.

TABLE 4 | Clinical and biological characteristics at admission of evaluable patients with or without baseline dabigatran $\geq 264 \mathrm{ng} / \mathrm{mL}$.

\begin{tabular}{lccc}
\hline Patient characteristics & $\begin{array}{c}\text { Dabigatran }< \\
\mathbf{2 6 4} \mathbf{n g} / \mathbf{m L} \\
(\boldsymbol{n}=\mathbf{2 6})\end{array}$ & $\begin{array}{c}\text { Dabigatran } \geq \\
\mathbf{2 6 4} \mathbf{n g} / \mathbf{m L} \\
(\boldsymbol{n}=\mathbf{2 1})\end{array}$ & p-value \\
\hline Age-year-mean $( \pm \mathrm{SD})$ & $80.4( \pm 12.5)$ & $83.6( \pm 8.8)$ & 0.39 \\
Male sex-n $(\%)$ & $23(69.7)$ & $6(42.9)$ & 0.16 \\
CrCl-mL/min-mean $( \pm S D)$ & $50.7( \pm 25.1)$ & $31.8( \pm 20.8)$ & $\mathbf{0 . 0 1 9}$ \\
BMl-kg/m²-mean $( \pm S D)$ & $25.2( \pm 2.8)$ & $27.7( \pm 6.5)$ & 0.16 \\
CHA 2 DS 2 -VASc & $3.4( \pm 1.4)$ & $4.2( \pm 1.9)$ & 0.16 \\
score-mean $( \pm S D)$ & & & \\
Hemoglobin g/L-mean & $111.3( \pm 30.1)$ & $90.4( \pm 22.4)$ & $\mathbf{0 . 0 2 8}$ \\
$( \pm S D)$ & & &
\end{tabular}

$\mathrm{BMI}$, body mass index; $\mathrm{CrCl}$, creatinine clearance. Bold values are corresponding to statistical differences with $p-$ value $<0.005$.

level (90.4 \pm 22.4 vs. $111.3 \mathrm{~g} / \mathrm{L} \pm 30.1, p=0.028)$. However, no difference in overall survival at 90 days was found between patients with plasma dabigatran $<$ or $\geq 264 \mathrm{ng} / \mathrm{mL}$ at admission (Figure 2A, $p=0.48$ ).

\section{Plasma Dabigatran Rebound After Reversal}

In RE-VERSE AD trial (1), efficacy of idarucizumab was defined as the capacity to reverse the dabigatran anticoagulant effect within $4 \mathrm{~h}$ after its administration in dabigatran-treated patients. 


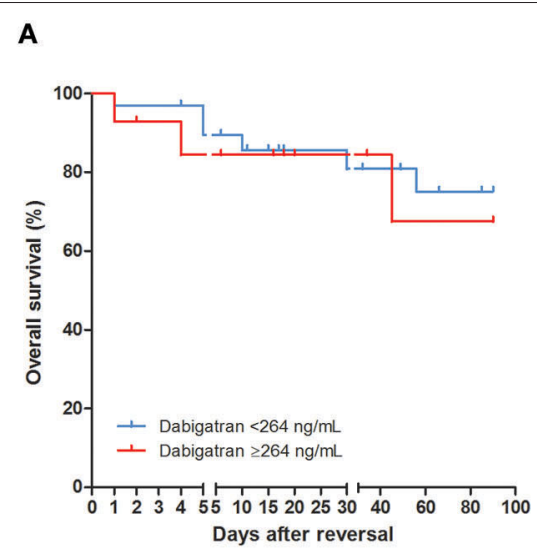

B

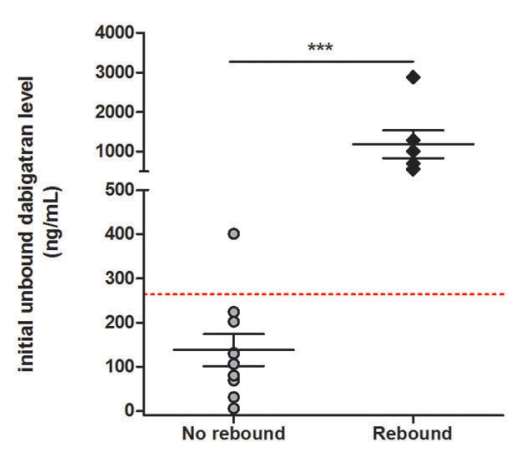

c

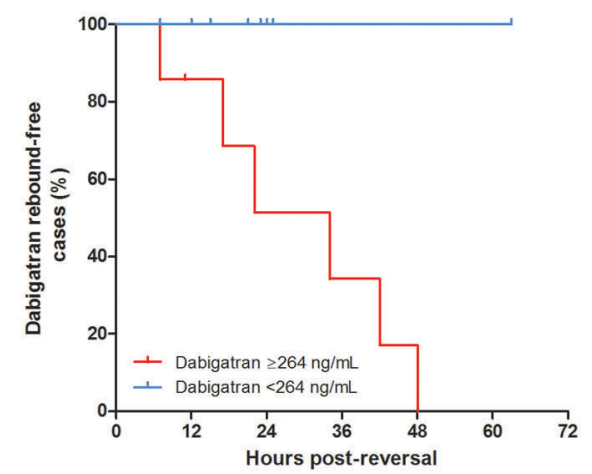

FIGURE 2 | Initial plasma dabigatran level and biological or clinical outcomes. (A) Kaplan-Meier 90-day survival curve patients after idarucizumab administration according to baseline plasma dabigatran cutoff of $264 \mathrm{ng} / \mathrm{mL}$. Percent survival rate was stratified by dabigatran plasma level at baseline $<$ or $\geq 264 \mathrm{ng} / \mathrm{mL}$ for $(n=33$ and 14 , respectively) and did not significantly differ between groups $(p=0.36)$. (B) Initial plasma dabigatran concentrations in patients according to the presence or absence of dabigatran rebound after idarucizumab. Among the 87 patients who had a laboratory test prior to idarucizumab injection, only 16 had plasma dabigatran determination both at baseline and during follow-up. At baseline, patients with no rebound had a significant lower mean of dabigatran level $(138 \mathrm{ng} / \mathrm{mL} \pm 114, p=$ $0.0002)$ than patients with rebound (1,189 ng/mL \pm 869 ). The dashed red line is a reference line indicating the predefined cutoff of $264 \mathrm{ng} / \mathrm{mL}$. (C) Proportion of cases of dabigatran rebound after reversal according to the cutoff of $264 \mathrm{ng} / \mathrm{mL}$ before reversal. No dabigatran rebound was observed after reversal in patients with dabigatran $<264 \mathrm{ng} / \mathrm{mL}$ at baseline ( $n=9$, blue bar). Among patients with dabigatran $\geq 264 \mathrm{ng} / \mathrm{mL}$ at baseline, rebound was observed in six patients within a median time of $34 \mathrm{~h}$ post-reversal (red bar).

In our study, only one case of incomplete reversal was observed in patient \#87 who had an initial dabigatran concentration of $2,881 \mathrm{ng} / \mathrm{mL}$. Dabigatran level dropped to $73 \mathrm{ng} / \mathrm{mL}$ within $30 \mathrm{~min}$ after reversal and re-increased to $870 \mathrm{ng} / \mathrm{mL} 6 \mathrm{~h}$ later. We noticed eight (42.1\%) reappearances of plasma dabigatran (mean $273 \mathrm{ng} / \mathrm{m} \pm 288$ ) between 7 and $48 \mathrm{~h}$ after idarucizumab infusion in 19 evaluable patients. When considering the 16 patients whose dabigatran plasma was measured both at baseline and during follow-up, patients experiencing dabigatran rebound had a significantly higher mean dabigatran concentration at admission $(1,189 \pm 869$ vs. $138 \mathrm{ng} / \mathrm{mL} \pm 114$, $p=0.0002$, Figure 2B).

Among the 16 patients with repeated measurements, seven patients had an initial plasma concentration $\geq 264 \mathrm{ng} / \mathrm{mL}$ and 9 patients $<264 \mathrm{ng} / \mathrm{mL}$. No plasma dabigatran rebound was observed after reversal in patients with dabigatran $<264 \mathrm{ng} / \mathrm{mL}$ at baseline. In contrast, six (85.7\%) patients with dabigatran $\geq 264 \mathrm{ng} / \mathrm{mL}$ at baseline had rebound within a mean time of $34 \mathrm{~h}$ post-reversal (Figure 2C). Patients with dabigatran rebound had a significantly higher mean $\mathrm{CHA}_{2} \mathrm{DS}_{2}$-VASc score ( $4.75 \pm 1.9$ vs. $3.10 \pm 1.2, p=0.039)$. Age, body mass index, plasma creatinine level, and $\mathrm{CrCl}$ were not associated with plasma dabigatran rebound ( $p>0.05$ for each, Table 5).

It should be noted that patient \#57 with baseline dabigatran at $401 \mathrm{ng} / \mathrm{mL}$ did not experience dabigatran rebound; however, it should be specified that dabigatran monitoring was performed only during the first $12 \mathrm{~h}$ post-reversal.

\section{DISCUSSION}

This study reports on the biological and clinical experience of dabigatran reversal with idarucizumab in 21 French centers. The main finding of this real-world based cohort study is that initial plasma level of dabigatran before reversal allows to predict both clinical hemostatic effectiveness and risk of plasma dabigatran rebound. In addition, we showed that patients with ineffective hemostasis after reversal had less favorable outcomes and a trend to increased mortality. We identified patients who could not achieve effective hemostasis and/or might have significant circulating dabigatran rebound after reversal and a potential risk of non-surgical or surgical bleeding related to this rebound. The proposed dabigatran cutoff of $264 \mathrm{ng} / \mathrm{mL}$ could help in managing patients with uncontrolled bleeding after a first idarucizumab infusion, or patients who require a powerful neutralization for example in case of intravenous thrombolysis for stroke. Levy et al. (23) showed in the RE-VERSE AD trial that the median time from the first vial of idarucizumab to surgery or procedures was $<2 \mathrm{~h}$ in all groups except neurosurgery, where it was $3.3 \mathrm{~h}$. Idarucizumab should indeed be injected without awaiting the laboratory results, but dabigatran level at admission could help in anticipating the need for subsequent injections and influence follow-up after reversal (Figure 3).

For patients presenting major bleeding according to the ISTH criteria (14), treatment with idarucizumab was considered effective in $77.2 \%$ of them. Hemostatic effectiveness was similar to that reported in a large Dutch cohort (67\%) (4). Among the entire cohort, $58.2 \%$ of evaluable patients received blood products or additional pro-hemostatic agents. The incidence of thrombotic events $(3.4 \%)$ was similar to that reported in the RE-VERSE AD trial (4.8\%), and none of these patients had any additional use of PCC or any other pro-hemostatic agents. Regarding thrombotic events, beyond the abrupt interruption of anticoagulation, there is also the risk resulting from immobilization, inflammation, surgery, and the overall context 
of intensive care, which makes the determination of the specific role of idarucizumab challenging in such events. We analyzed the use of idarucizumab in a real-world setting without questioning the indication for dabigatran reversal criteria followed by each center.

DOACs do not require biological monitoring since they have predictable pharmacokinetics and therapeutic effects (10). Idarucizumab is recommended at a single dose of $5 \mathrm{~g}(2.5 \mathrm{~g}$ $\times 2$ ), calculated to reverse in a stoichiometric way the total body load of dabigatran that was associated with the 99th percentile of the dabigatran levels measured in the phase III

TABLE 5 | Clinical and biological characteristics at admission of evaluable patients with or without dabigatran rebound after dabigatran reversal.

\begin{tabular}{lccc}
\hline Patient characteristics & $\begin{array}{c}\text { No rebound } \\
(\boldsymbol{n}=\mathbf{1 1})\end{array}$ & $\begin{array}{c}\text { Rebound } \\
(\boldsymbol{n}=\mathbf{8})\end{array}$ & $\boldsymbol{p}$-Value \\
\hline Age-year-mean $( \pm \mathrm{SD})$ & $80.73( \pm 10.4)$ & $74.75( \pm 23.9)$ & 0.46 \\
Male sex-n $\%)$ & $9(81.8)$ & $3(37.5)$ & 0.13 \\
$\mathrm{CHA}_{2} \mathrm{DS}_{2}$-VASc score-mean & $3.10( \pm 1.2)$ & $4.75( \pm 1.9)$ & $\mathbf{0 . 0 3 9}$ \\
$( \pm \mathrm{SD})$ & & & \\
$\mathrm{BMl}-\mathrm{kg} / \mathrm{m}^{2}-$ mean $( \pm \mathrm{SD})$ & $28.2( \pm 3.5)$ & $27.0( \pm 7.7)$ & 0.76 \\
$\mathrm{CrCl}-\mathrm{mL} /$ min-mean $( \pm \mathrm{SD})$ & $62.2( \pm 34.5)$ & $28.5( \pm 25.3)$ & 0.054 \\
Hemoglobin g/L-mean $( \pm \mathrm{SD})$ & $113.8( \pm 28.7)$ & $117.7( \pm 48.9)$ & 0.83 \\
Dabigatran-ng/mL-mean & $138.0( \pm 115)$ & $1,189.33$ & $\mathbf{0 . 0 0 0 2}$ \\
$( \pm \mathrm{SD})$ & & $( \pm 870)$ & \\
\hline
\end{tabular}

$\mathrm{BMI}$, body mass index; $\mathrm{CrCl}$, creatinine clearance. Bold values are corresponding to statistical differences with $p-$ value $<0.005$. study RE-LY. However, a single $5 \mathrm{~g}$ dose of idarucizumab would not be sufficient to completely reverse the effect of dabigatran in all cases. In RE-VERSE AD (1), the authors observed a plasma dabigatran rebound within $12 \mathrm{~h}$ post-reversal in $23 \%$ of the cases, and this rebound was associated with recurrent or continued bleeding in $9 \%$ of them, leading the investigators to consider a second administration of idarucizumab. In the present study, four (4.6\%) patients received two or more injections of idarucizumab. Among them, three had a dabigatran initial concentration above $264 \mathrm{ng} / \mathrm{mL}$ (see Supplementary Table 4), similar to what was observed in the seven patients of the REVERSE AD trial (1) with re-bleeding and/or post-operative bleeding and who had a second injection of idarucizumab. In the RE-VECTO surveillance program (24), five bleeding patients required a second idarucizumab infusion for rebleeding/prolonged coagulation test $(n=4)$ or for an additional urgent intervention $(n=1)$ suggesting insufficient hemostatic effectiveness after the first $5 \mathrm{~g}$ of infusion. As we previously showed $(3,25)$, the present study reports that bleeding patients had higher dabigatran levels at baseline compared to REVERSE$\mathrm{AD}$ (337 vs. $110 \mathrm{ng} / \mathrm{mL})$.

When assessing clinical hemostatic efficacy of idarucizumab treatment according to dabigatran concentration at admission, we determined a cutoff of $264 \mathrm{ng} / \mathrm{mL}$ as a predictor of efficacy. Moreover, patients with dabigatran rebound after reversal had dabigatran level at baseline above $264 \mathrm{ng} / \mathrm{mL}$, a value close to the $200 \mathrm{ng} / \mathrm{mL}$ cutoff we previously suggested elsewhere (3). Dabigatran rebound is thought to occur as a result of redistribution in plasma of unbound dabigatran from the

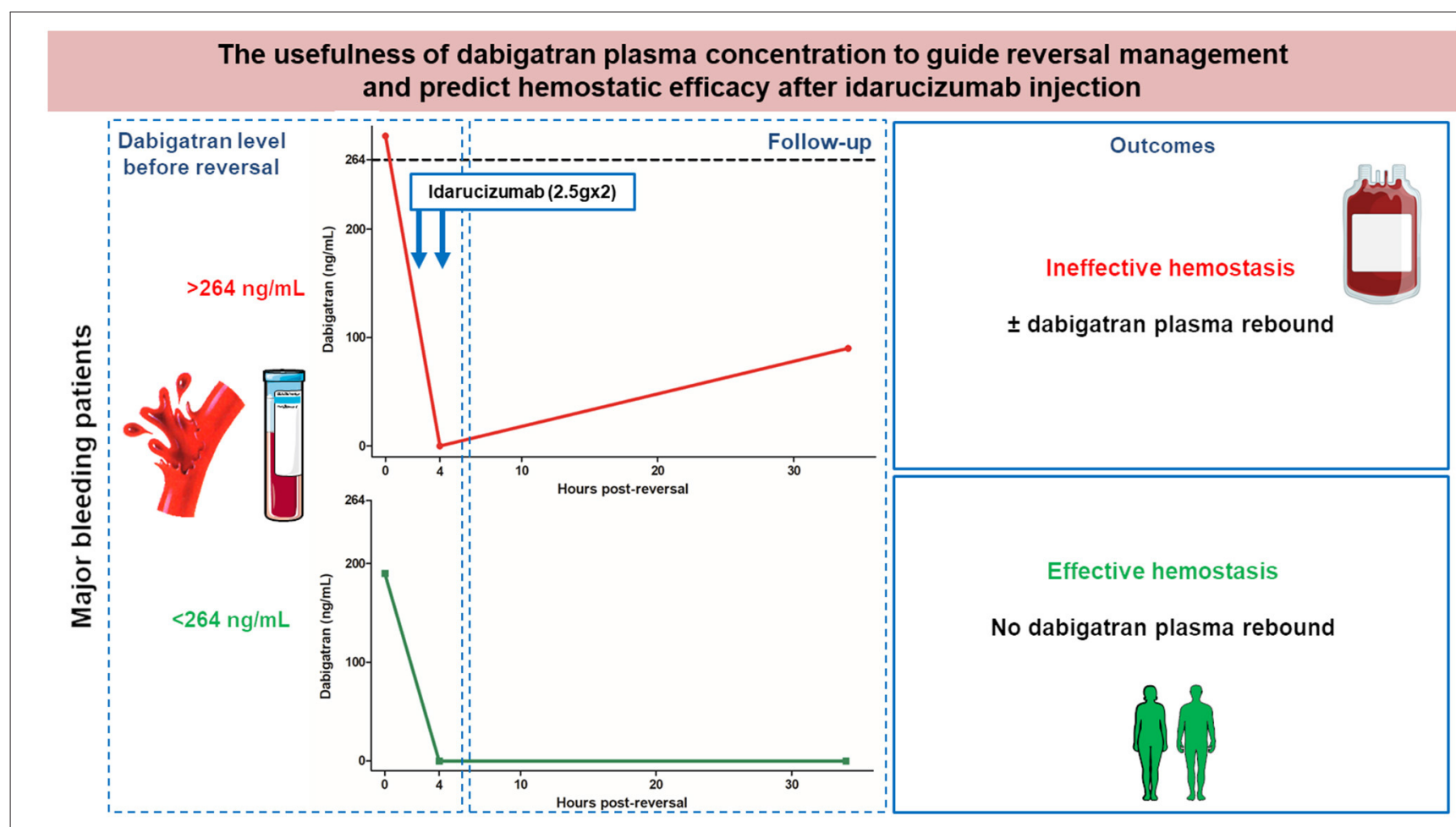

FIGURE 3 | The usefulness of dabigatran plasma concentration to guide reversal management and predict hemostatic efficacy after idarucizumab injection. 
peripheral tissues to the intravascular compartment over time after idarucizumab clearance, in response to the concentration gradient occurring after neutralization as previously observed in healthy volunteers (26). Dabigatran and idarucizumab are both cleared by the kidneys. Recently, Eikelboom et al. (27) evaluated the impact of renal impairment on the effect of dabigatran reversal by idarucizumab in RE-VERSE AD. They showed that dabigatran rebound within $12-24 \mathrm{~h}$ was more common in patients with renal impairment, whereas time to bleeding cessation and extent of hemostasis during procedures were independent of renal function. Our results are similar, as hemostatic effectiveness did not correlate with renal function. It is important to consider that renal function is not a static measure, and in both RE-VERSE AD and the present study, it was only assessed before dabigatran reversal. Moreover, we found no significant difference between plasma creatinine level and $\mathrm{CrCl}$ in patients with or without plasma dabigatran rebound after reversal as previously described by our team (3). Furthermore, Glund et al. (28) showed that subjects with mild or moderate renal impairment had an increased exposure, a decreased clearance, and a prolonged half-life of idarucizumab compared to healthy subjects. Hence, according to our results, hemostatic efficacy would be driven by a balance between dabigatran extravascular accumulation/redistribution and the neutralization capacity of circulating idarucizumab along time.

There are several limitations to consider with respect to our study. First, the retrospective design of the present study based on reported cases could limit data quality. Large-scale registers of the use of idarucizumab are still needed and should be implemented by dabigatran monitoring at baseline and during reversal to analyze the clinical relevance of dabigatran rebound. Second, as in the RE-VERSE AD study, the lack of a control group and the small number of patients may limit the strength of the conclusions.

In summary, our study shows that dabigatran level at admission is a major tool to predict clinical hemostasis upon idarucizumab reversal as well as plasma dabigatran rebound. Using a cutoff of $264 \mathrm{ng} / \mathrm{mL}$, plasma dabigatran before reversal in patients with major bleeding allows indeed to predict hemostatic ineffectiveness, dabigatran rebound, and outcomes after reversal. Dabigatran level before reversal is not intended to "treat or not-treat" but to select patients that might need a specific

\section{REFERENCES}

1. Pollack CV, Reilly PA, van Ryn J, Eikelboom JW, Glund S, Bernstein RA, et al. Idarucizumab for dabigatran reversal-full cohort analysis. $N$ Engl J Med. (2017) 377:431-41. doi: 10.1056/NEJMoa1707278

2. Gendron N, Feral-Pierssens AL, Jurcisin I, de Raucourt E, Bouton V, Fischer AM, et al. Real-world use of idarucizumab for dabigatran reversal in three cases of serious bleeding. Clin Case Rep. (2017) 5:346-50. doi: $10.1002 / \mathrm{ccr} 3.839$

3. Gendron N, Gay J, Lemoine M, Gaussem P, Lillo-Le-Louet A, Smadja DM. Usefulness of initial plasma dabigatran concentration to predict rebound after reversal. Haematologica. (2018) 103:e226-9. doi: 10.3324 /haematol.2017.183400 follow-up after reversal with idarucizumab. The proposed cutoff should be included in further prospective studies to be validated.

\section{DATA AVAILABILITY STATEMENT}

The raw data supporting the conclusions of this article will be made available by the authors, without undue reservation.

\section{ETHICS STATEMENT}

The studies involving human participants were reviewed and approved by the institutional review board of each center and anonymous data collection was declared to the appropriate authorities (Authorization protocol number: CNIL-1922081). Written informed consent for participation was not required for this study in accordance with the national legislation and the institutional requirements.

\section{AUTHOR CONTRIBUTIONS}

NG, RC, ALL, and DS conceived and supervised the study. NG, $\mathrm{RC}, \mathrm{PB}, \mathrm{ALL}$, and DS analyzed and interpreted the data. RC analyzed the data and supervised the statistical analysis. NG, RC, PB, PG, and DS wrote the manuscript. All authors managed and included patient cases. All authors revised the manuscript and approved the final version.

\section{ACKNOWLEDGMENTS}

We would like to acknowledge Dr. Luc-Marie Joly à Rouen (Emergency Department, Rouen University Hospital, Rouen, France), Dr. Marie-Charlotte Bourrienne (Laboratory of Hematology, Hôpital Bichat-Claude Bernard, AP-HP, Paris, France), and Dr. Pierre Parrein (Pharmacy Department, Dieppe, France) for their help in including patients in the cohort and for contributing to data retrieval.

\section{SUPPLEMENTARY MATERIAL}

The Supplementary Material for this article can be found online at: https://www.frontiersin.org/articles/10.3389/fmed. 2020.599626/full\#supplementary-material
4. van der Wall SJ, van Rein N, van den Bemt B, Kruip MJHA, Meijer $\mathrm{K}$, Te Boome LCJ, et al. Performance of idarucizumab as antidote of dabigatran in daily clinical practice. Europace. (2019) 21:414-20. doi: 10.1093/europace/euy220

5. Singh S, Nautiyal A, Belk KW. Real world outcomes associated with idarucizumab: population-based retrospective cohort study. Am J Cardiovasc Drugs. (2019) 20:161-8. doi: 10.1007/s40256-019-00360-6

6. Kermer P, Eschenfelder CC, Diener H-C, Grond M, Abdalla Y, Abraham A, et al. Antagonizing dabigatran by idarucizumab in cases of ischemic stroke or intracranial hemorrhage in Germany-updated series of 120 cases. Int J Stroke. (2020)1747493019895654. doi: 10.1177/1747493019895654

7. Levy JH, Ageno W, Chan NC, Crowther M, Verhamme P, Weitz JI, et al. When and how to use antidotes for the reversal of direct oral anticoagulants: 
guidance from the SSC of the ISTH. J Thromb Haemost. (2016) 14:623-7. doi: $10.1111 /$ jth. 13227

8. Rottenstreich A, Jahshan N, Avraham L, Kalish Y. Idarucizumab for dabigatran reversal-does one dose fit all? Thromb Res. (2016) 146:103-4. doi: 10.1016/j.thromres.2016.09.006

9. Brennan Y, Favaloro EJ, Pasalic L, Keenan H, Curnow J. Lessons learnt from local real-life experience with idarucizumab for the reversal of dabigatran. Intern Med J. (2019) 49:59-65. doi: 10.1111/imj.13995

10. Gosselin RC, Adcock DM, Bates SM, Douxfils J, Favaloro EJ, Gouin-Thibault I, et al. International Council for Standardization in Haematology (ICSH) recommendations for laboratory measurement of direct oral anticoagulants. Thromb Haemost. (2018) 118:437-50. doi: 10.1055/s-0038-1627480

11. Godier A, Dincq A-S, Martin A-C, Radu A, Leblanc I, Antona M, et al. Predictors of pre-procedural concentrations of direct oral anticoagulants: a prospective multicentre study. Eur Heart J. (2017) 38:2431-9. doi: 10.1093/eurheartj/ehx403

12. Schulman S, Kearon C, Subcommittee on Control of Anticoagulation of the Scientific and Standardization Committee of the International Society on Thrombosis and Haemostasis. Definition of major bleeding in clinical investigations of antihemostatic medicinal products in non-surgical patients. J Thromb Haemost. (2005) 3:692-4. doi: 10.1111/j.1538-7836.2005. 01204.x

13. Kaatz S, Ahmad D, Spyropoulos AC, Schulman S, Subcommittee on Control of Anticoagulation. Definition of clinically relevant non-major bleeding in studies of anticoagulants in atrial fibrillation and venous thromboembolic disease in non-surgical patients: communication from the SSC of the ISTH. J Thromb Haemost. (2015) 13:2119-26. doi: 10.1111/jth. 13140

14. Khorsand N, Majeed A, Sarode R, Beyer-Westendorf J, Schulman S, Meijer $\mathrm{K}$, Subcommittee on Control of Anticoagulation. Assessment of effectiveness of major bleeding management: proposed definitions for effective hemostasis: communication from the SSC of the ISTH. J Thromb Haemost. (2016) 14:2114. doi: $10.1111 /$ jth. 13148

15. Jung S-H. Stratified Fisher's exact test and its sample size calculation. Biom J. (2014) 56:129-40. doi: 10.1002/bimj.201300048

16. Mishra P, Pandey CM, Singh U, Keshri A, Sabaretnam M. Selection of appropriate statistical methods for data analysis. Ann Card Anaesth. (2019) 22:297-301. doi: 10.4103/aca.ACA_248_18

17. Zhang B, Zhang Y. Mann-Whitney $U$ test and Kruskal-Wallis test should be used for comparisons of differences in medians, not means: comment on the article by van der Helm-van Mil et al. Arthritis Rheum. (2009) 60:1565; author reply 1565. doi: 10.1002/art.24497

18. Hajian-Tilaki K. Receiver Operating Characteristic (ROC) curve analysis for medical diagnostic test evaluation. Caspian J Intern Med. (2013) 4:627-35.

19. Park SH, Goo JM, Jo C-H. Receiver operating characteristic (ROC) curve: practical review for radiologists. Korean J Radiol. (2004) 5:11-8. doi: $10.3348 / \mathrm{kjr} .2004 .5 .1 .11$

20. Zee J, Xie SX. The Kaplan-Meier method for estimating and comparing proportions in a randomized controlled trial with dropouts. Biostat Epidemiol. (2018) 2:23-33. doi: 10.1080/24709360.2017.1407866

21. Goel MK, Khanna P, Kishore J. Understanding survival analysis: Kaplan-Meier estimate. Int $J$ Ayurveda Res. (2010) 1:274-8. doi: 10.4103/0974-7788.76794
22. Reichenheim ME, Coutinho ES. Measures and models for causal inference in cross-sectional studies: arguments for the appropriateness of the prevalence odds ratio and related logistic regression. BMC Med Res Methodol. (2010) 10:66. doi: 10.1186/1471-2288-10-66

23. Levy JH, van Ryn J, Sellke FW, Reilly PA, Elsaesser A, Glund S, et al. Dabigatran reversal with idarucizumab in patients requiring urgent surgery: a subanalysis of the RE-VERSE AD study. Ann Surg. (2019) 1-8. doi: $10.1097 /$ SLA.0000000000003638

24. Fanikos J, Murwin D, Gruenenfelder F, Tartakovsky I, França LR, Reilly $\mathrm{PA}$, et al. Global use of idarucizumab in clinical practice: outcomes of the RE-VECTO surveillance program. Thromb Haemost. (2020) 120:27-35. doi: $10.1055 / \mathrm{s}-0039-1695771$

25. Billoir P, Girault C, Barbay V, Boyer D, Grangé S, Fresel M, et al. Management of dabigatran after overdosage: two case reports and suggestions for monitoring. Blood Coagul Fibrinolysis. (2018) 29:653-5. doi: 10.1097/MBC.0000000000000763

26. Glund S, Stangier J, Schmohl M, Gansser D, Norris S, van Ryn J, et al. Safety, tolerability, and efficacy of idarucizumab for the reversal of the anticoagulant effect of dabigatran in healthy male volunteers: a randomised, placebo-controlled, double-blind phase 1 trial. Lancet. (2015) 386:680-90. doi: 10.1016/S0140-6736(15)60732-2

27. Eikelboom JW, van Ryn J, Reilly P, Hylek EM, Elsaesser A, Glund S, et al. Dabigatran reversal with idarucizumab in patients with renal impairment. $J$ Am Coll Cardiol. (2019) 74:1760-8. doi: 10.1016/j.jacc.2019.07.070

28. Glund S, Stangier J, Ryn J van, Schmohl M, Moschetti V, et al. Effect of age and renal function on idarucizumab pharmacokinetics and idarucizumabmediated reversal of dabigatran anticoagulant activity in a randomized, double-blind, crossover phase Ib study. Clin Pharmacokinet. (2017) 56:41-54. doi: 10.1007/s40262-016-0417-0

Conflict of Interest: NG discloses consulting fees by Boehringer Ingelheim, Bayer, Bristol-Myers Squibb/Pfizer and LEO Pharma. RC reports consulting fees from Aspen. A-CM discloses consulting fees from Bayer and Boehringer Ingelheim, and consulting fees and grant from Bristol-Myers-Squibb/Pfizer. ALL discloses consulting fees by Boehringer Ingelheim and Bayer. LB reports personal fees and non-financial support from Aspen, Actelion, Bayer, LEO-pharma, Bristol-Myers Squibb/Pfizer, and MSD; non-financial support from Daiichi; and grants and personal fees from Sanofi outside the submitted work. DS declares consulting fees from Bayer, Bristol-Myers Squibb/Pfizer, Boehringer Ingelheim, Aspen, and LEO-Pharma.

The remaining authors declare that the research was conducted in the absence of any commercial or financial relationships that could be construed as a potential conflict of interest.

Copyright $\odot 2020$ Gendron, Chocron, Billoir, Brunier, Camoin-Jau, Tuffigo, Faille, Teissandier, Gay, de Raucourt, Suner, Bonnet, Martin, Lasne, Ladhari, Lebreton, Bertoletti, Ajzenberg, Gaussem, Morange, Le Cam Duchez, Viallon, Roy, Lillole Louet and Smadja. This is an open-access article distributed under the terms of the Creative Commons Attribution License (CC BY). The use, distribution or reproduction in other forums is permitted, provided the original author(s) and the copyright owner(s) are credited and that the original publication in this journal is cited, in accordance with accepted academic practice. No use, distribution or reproduction is permitted which does not comply with these terms. 